\title{
026 SEXUALITY AT END OF LIFE: THE SILENT BEDFELLOW
}

Bridget Taylor Sobell House Hospice, Oxford, UK

10.1136/bmjspcare-2012-000196.26

Background Sexuality is a holistic concept that includes physical, psychological and social aspects of people's well-being. As the aim of palliative care includes supporting patients to live as actively as possible until death, as well as supporting those that are significant to them, it would seem reasonable to expect that sexuality would be included. However, what is not clear is whether sexuality continues to be important for people in the UK who are dying.

Aim To understand the experiences of patients and partners of patients living with a life-limiting illness in relation to sexuality and intimacy.

Method This qualitative study used a Heideggerian hermeneutic methodology. One-to-one interviews were conducted with 27 patients and 14 partners of patients who had either motor neurone disease or terminal cancer. Each person was interviewed twice and couples were interviewed separately. Audio-recorded data were analysed using Diekelmann and Ironside's seven-stage process to uncover shared meanings. This iterative process is fundamental to Heidegger's hermeneutic circle of interpretation.

Findings This paper presents one of the themes, 'the silent bedfellow'. Participants described times 'when words fail' and they experienced 'disconnecting' within their coupled relationship. In contrast, 'when words speak' brought about 'connecting', even though this was not always in ways that had been expected. It was rare for people to be given opportunities to discuss their fears or concerns about sexuality with palliative care professionals. Participants gave practical suggestions for ways that professionals can broach this aspect of people's relationships.

Conclusions Palliative care professionals who support holistic care and promote quality of life have a role in providing opportunities for discussing these issues with patients and their partners. 